\title{
El Examen Nacional de Medicina (ENAM) y su rol en Perú
}

The National Medical Examination (ENAM) and its role in Peru

Brayan Gálvez-Marticorena ${ }^{1}$

Sr. Editor:

El Examen Nacional de Medicina (ENAM) es un examen escrito tipo objetivo, con 200 preguntas de selección múltiple y razonamiento clínico en base a casos; diseñado para medir los conocimientos y razonamiento fundamentales del futuro médico general, organizado por la Asociación Peruana de Facultades de Medicina (ASPEFAM) y dirigido a los que estén cursando el internado médico (1).

Los objetivos del ENAM se describen en la tabla 1.

Tabla 1. Tabla1. Objetivos del ENAM establecidos por la ASPEFAM

\begin{tabular}{|c|c|}
\hline & Objetivos \\
\hline • & $\begin{array}{l}\text { Evaluar los conocimientos en ciencias básicas, ciencias clínicas, y en salud } \\
\text { pública. }\end{array}$ \\
\hline - & $\begin{array}{l}\text { Brindar información objetiva a las Facultades o Escuelas de Medicina y a los } \\
\text { estudiantes. }\end{array}$ \\
\hline • & Promover el mejoramiento de la Educación Médica. \\
\hline - & $\begin{array}{l}\text { Promover la revisión crítica del perfil de formación y una cultura de evaluación } \\
\text { del desempeño institucional en la formación de los médicos generales. }\end{array}$ \\
\hline • & $\begin{array}{l}\text { Establecer un referente nacional de evaluación válido y objetivo de los } \\
\text { conocimientos médicos, reconocido por instituciones formadoras y prestadoras } \\
\text { de servicios de salud. }\end{array}$ \\
\hline
\end{tabular}

Desde el 2006, es requisito para postular al Residentado Médico y desde el 2008, la calificación del ENAM, vale $70 \%$ para la distribución de las plazas de SERUMS (1).

Considero que presentar los resultados del ENAM, por universidad, como media aritmética no es adecuado, dado que las medidas de tendencia central deben ser acordes a la distribución de las calificaciones.
Los valores extremos, tienen un efecto importante en el promedio de poblaciones pequeñas (2) que es lo usual en las promociones universitarias.

En cuanto al puesto, logrado por cada facultad, se esperaría una sostenibilidad de los resultados de un año a otro, pero no ocurre (3). El examen es inconsistente en la exploración del contenido y profundidad de los diferentes ámbitos de un año a otro (3).

Estudiante de pre grado de Medicina Humana, Facultad de Medicina Humana, Universidad de San Martín de Porres, Lima, Perú. 
La nota ENAM es baja en médicos procedentes del extranjero, posiblemente por la variación epidemiológica y el enfoque de la formación en cada país (4).

La enseñanza de la medicina es la enseñanza de un grupo de saberes que se relacionan con lo que el médico tiene que saber (conocimientos), lo que tiene que saber hacer (habilidades) y cómo tiene que ser (valores profesionales) (5). El ENAM no predice las dos últimas, ni pondera adecuadamente las ciencias básicas (refleja procesos de aprendizaje de mayor antigüedad, a diferencia de las ciencias clínicas).

Las pruebas de conocimientos son medidas diagnósticas que requieren menos recursos que una integral (incluye aspecto procedimental y actitudinal), por lo que un análisis de costo efectividad nos daría una visión más completa del asunto (1).

Por estas observaciones y porque la evaluación médica se va perfeccionando, no se puede concluir en base al ENAM que Facultad de Medicina Humana es la mejor, ni es justificable publicitarse de acuerdo al resultado que se obtenga.

\section{REFERENCIAS BIBLIOGRÁFICAS}

1. Examen Nacional de Facultades de Medicina - ENAM (ASPEFAM) [Internet]. [citado 19 de julio de 2014]. Recuperado a partir de: http:// www. aspefam. org. pe/ enam/

2. Huamaní C, Gutiérrez C, Mezones-Holguín E . Correlación y concordancia entre el examen nacional de medicina y el promedio ponderado universitario : Análisis de la experiencia peruana en el período 2007-2009. Rev Peru Med Exp Salud Publica. 2011; 28(1): $62-71$

3. Cieza Zevallos J, León Rabanal C, Huapaya Carrera J, Miyahira Arakaki J .Examen Nacional de medicina en Perú 2008-2009: análisis y sostenibilidad de los resultados. Acta Med Per. 2010;27(2):99-104

4. Moreno-Loaiza M, Mamani-Quispe P,Moreno-Loaiza 0 .Diferencias entre el promedio ponderado promocional y la nota del examen nacional de medicina en el proceso de adjudicación de plazas para el servicio rural y urbano marginal de salud. Rev Peru Med Exp Salud Publica .2013; 30(2)360-362

5. Millán J .La enseñanza de las habilidades clínicas.Educ Med .2008; 11(supl):S21-S27

\section{Fuente de Financiamiento}

Autofinanciado por el autor.

\section{Conflictos de interés}

El autor declara no tener conflictos de interés en la publicación de este artículo.

\section{Correspondencia:}

Brayan Gálvez Marticorena

Dirección: Av. El Corregidor 1531. La Molina, LimaPerú

Teléfono: 3652300

Correo electrónico: brayan_galvez@usmp.pe 